\title{
Sanctuary sites and compartments: deciphering the enigma
}

\begin{abstract}
Avishek Amar*
Department of Pharmacology, JIPMER, Pondicherry, India

Received: 28 April 2018 Accepted: 26 May 2018

*Correspondence to:

Dr. Avishek Amar,

Email: dravishekamar@ gmail.com

Copyright: (C) the author(s), publisher and licensee Medip Academy. This is an openaccess article distributed under the terms of the Creative Commons Attribution NonCommercial License, which permits unrestricted noncommercial use, distribution, and reproduction in any medium, provided the original work is properly cited.

ABSTRACT

It has been a common observation that many drugs get accumulated in the body at certain sites labelled as anatomical or physiological compartments where they are not expected to exert their desired effect. While the field of pharmacology considers these so-called sites or imaginary compartments as "sanctuary compartments" which could comprise of specialised tissue system where drugs could bind to tissue proteins or nucleoproteins, adipose cells serving as reservoir for extensively lipid soluble drugs, aqueous humour, cerebrospinal fluid, bones, and even plasma proteins, the reach and impact of the sanctuary compartments or sanctuary sites (which is the more preferred and broader term) has grown beyond that and spread extensively. Now, it is not just about certain drugs finding safe haven in these sanctuary compartments but also about certain disease conditions like HIV infection and cancer doing the same. Evidence has been accumulating regarding the fact that human immunodeficiency virus and various type of cancer cells have been using these compartments or sites to avoid being exposed to drugs which cannot penetrate well into such sanctuary sites. This phenomenon over the period of time has culminated in the development of resistance towards antiretroviral and anti-neoplastic drugs to name a few. This means of acquired resistance is proving to be a major barrier to providing effective treatment to the patients. This review focusses on sanctuary compartments, their basic idea, the benefits associated with them, the challenges it poses to modern day medicine and finally, the possible methods of overcoming those challenges by attempting to un-sanctify the sanctuary compartments.
\end{abstract}

Keywords: HIV, HAART, Metatstasis, Sanctuary sites, Sanctuary compartment

\section{INTRODUCTION}

\section{Sanctuary compartment: the entity}

It is a well-known fact that the distribution of drugs in the body is often not uniform, irrespective of the route of administration of the drug. ${ }^{1,2}$ The reasons of this selective distribution of drugs to certain compartments can range from the fact that certain drugs have higher affinity to certain types of tissues in the body to the drugs own physicochemical attributes which themselves can play a role in selective presence of certain drugs in certain regions of the body. In addition, the rate of delivery of the drug to various organs which depends on the blood perfusion of the organ system or tissues also contributes to this phenomenon of selective distribution. While, the first share of the administered drug reaches the vital organs like liver, kidneys and other highly perfused organs the next phase attempts the distribution of drugs over the complete body mass over a period of time and finally it reaches to a state of equilibrium between the tissues and the blood. ${ }^{3}$

Certain tissues in the body, at times act as isolated entities or compartments which could vary from being a physiological separation to an anatomical separation. At times, these sites may not be the one where the drug exerts its effects but simply serve the job of providing safe haven to such drugs where they could stay for quite a long duration of time. Such compartments or reservoirs are labelled as sanctuary compartments. 


\section{Are sanctuary compartment and sanctuary site, the same?}

The body comprises of several potential sites ranging from plasma proteins to specialised tissues like liver, heart and connectives tissues to adipose cells. Each one is individually specialised to function as a sanctuary compartment for certain drugs based on the properties of drugs and the concerned tissue. ${ }^{4}$

Similarly, there are certain anatomical locations in the body which are accessible to certain types of cells and microorganisms but not to the drugs countering those organisms and cells. Be it metastatic cancer cells finding refuge in the brain and spinal tract or HIV avoiding the anti-retroviral drugs in the genital tract, placenta and amniotic fluid. As these sites provide the much-needed safe haven or refuge to these drugs, microorganisms and cells like human immunodeficiency virus (HIV) and metastatic cancer cells these are known as sanctuary compartments or sanctuary sites. While these sites allow the drugs to avoid being metabolised, they provide human immunodeficiency virus or metastatic cancer cells protection from the action of anti-retroviral drugs and antineoplastic drugs. Over the period of time the idea of sanctuary compartments has evolved significantly in the wake of alarm raised by various studies with regards to HIV and metastatic cancer cells seeking refuge in these sanctuary sites to avoid being negated. This has led to the use of the broader umbrella term like sanctuary site becoming the more preferred one as it covers the drugs, microorganisms and cells together. ${ }^{5-7}$

\section{RESERVOIRS FOR DRUGS WHICH ACT AS SANCTUARY SITES}

There are drugs which could bind to tissue proteins and exhibit selective deposition in certain tissues. As seen with a drug like Digoxin which shows selective deposition in muscles of heart, liver and skeletal system. ${ }^{8,9}$ Similarly, Chloroquine too tends to accumulate in the liver as it concentrates in the lysosomes of the cells especially those of liver. ${ }^{10}$

Adipose tissue too has been famous in this regard to serve as a site of refuge to some compounds and drugs in the body. Evidence regarding accumulation of organic compounds like (dichlorodiphenyltrichloroethane) DDT, Lindane etc. in the adipocytes is widely available and the fact that they can be slowly released in the circulation too is widely known. ${ }^{11}$ Another well-known drug depositing in the adipocytes is Thiopental which attributing to its high affinity to lipids preferably deposits in the adipocytes. ${ }^{12}$

Antibiotic, Chloramphenicol has been found to be reaching and accumulating in the aqueous humor. Similarly cornea can serve as reservoir for drugs like Pilocarpine as it was reported that concentration of pilocarpine stayed higher in the cornea in comparison to aqueous humor for at least 4 hours. ${ }^{13,14}$ On a similar note high affinity of the antidepressant Imipramine to the lung tissue has also been reported as imipramine binding sites are present in the lungs which exhibit a preferential affinity for the drug. ${ }^{15}$

Another well-known site in the body known for its reservoir abilities towards many drugs is bone. Metals like lead, chromium etc. which do not intend to work upon bone tissues can prove to be a problem by finding shelter in the bones. ${ }^{16}$ Another, well-known site for drug deposition are skin and finger nails. Certain drugs show affinity for the keratin protein in the stratum corneum layer of the skin. This ability has been used to benefit with drugs such as Griseofulvin for nail infections and topical corticosteroids. ${ }^{17,18}$

Last but not the least, a widely known entity, the plasma proteins like albumin too play the role of sanctuary compartments in the body to some extent. The drugs attached to these proteins are cleared off from the system slowly and can exert their action for prolonged duration of time as and when becoming free from the drug - protein complex. Thus, an extensive binding to the proteins can prolong the availability of the drug in the system and its duration of action. ${ }^{19}$

\section{RESERVOIRS FOR MICROORGANISMS AND CANCER CELLS WHICH ACT AS SANCTUARY SITES}

About 2 decades or so back the discovery regarding the fact that human immunodeficiency virus can use certain sites in the human body to escape from the anti-retroviral drugs because these drugs cannot penetrate into these sites seems to have caught the clinician's attention. At the same time it also helped in solving the mystery behind ineffectiveness of Highly active antiretroviral therapy (HAART) in eradicating the HIV-1 virus from the body in certain cases. Similarly, certain types of solid cancers and cancer of the lymphatic tissue have led to the spread of metastatic cells to the central nervous system thus providing the metastatic cells an environment suitable enough to proliferate and invade further. ${ }^{20}$

\section{The possible sanctuary sites for HIV virus are}

\section{Gut and rectal associated lymphoid tissue}

The gut and the rectum have an abundance of lymphoid tissue, commonly known as gut-associated lymphoid tissue (GALT) and rectal-associated lymphoid tissue (RALT) respectively. These structures serve as one of the most vital sanctuary sites for HIV. The virus takes shelter in these tissues proliferates in here and escapes antiretroviral drugs effectively. Even the infected $\mathrm{T}$ cells present in the gut serve as a reservoir of HIV. ${ }^{2,21}$ It was also observed that virus isolated from the GALT and the peripheral blood mononuclear cells did have a lot of similarity which indicated that these GALTs are not only 
allowing the virus to take refuge but also to proliferate and further infect the circulating cells. ${ }^{2}$

Additionally, it was also concluded that the replication and proliferation of HIV-1 was an ongoing process even when there was no HIV RNA detected in the plasma. It was also noted that the overall concentration of the virus was higher along the whole of the gastrointestinal tract. Possible explanation for this could be the fact that expression of the enzymes responsible to metabolise the drugs may not be identical along the gastrointestinal tract. As a result difference in the concentration of the anti-retroviral drugs happens at different sites throughout the gastrointestinal tract. $^{2}$ This observation was supported by the fact that different transporters like P-glycoprotein (P-gp) and multidrug resistant protein (MRP-2) have different extents of expression along the gastrointestinal tract. The colon too, showed a higher expression of monocarboxylate transporter 1 (MCT-1) and MRP-3 in comparison to rest of the gastrointestinal tract. ${ }^{22}$

Even the expression of CYP enzymes especially CYP3A was found to be more in the proximal part of the gastrointestinal tract. Possibly, all these factors could have contributed to the establishment of sanctuary sites for the virus to proliferate and escape from being eliminated from the system. ${ }^{2}$

\section{Genital tract and foetal compartments}

The presence of HIV within the so called anatomically distinct sanctuary sites like genital tract has been noted and at the same time a below normal levels of anti-retroviral drugs at such sites indicates their ineffectiveness in penetrating these sites efficiently. This leads to unchecked virus proliferation and re-entry into the circulation even in the presence of prolonged anti-retroviral therapy. The penetration of the anti-retrovirals in the seminal fluid was reported to be the lowest for protease inhibitors. It was observed that the secretion of the anti-retrovirals into the genital tract also depends on the protein binding ability of the drugs. While Indinavir is secreted significantly in the genital tract, Lopinavir being about $99 \%$ protein bound is not. ${ }^{6}$

The work by Nicol et al, demonstrated that anti-retroviral secretion in the male genital tract was inversely related to the extent of protein binding of the drug. But this association was not seen in case of female genital tract. ${ }^{23}$

Structures like placenta and amniotic fluid too, have been reported to be functioning as sanctuary sites because the concentration of the drugs reaching them at certain instances are not up to the level needed to inhibit the virus completely which can reach these sites in use them for multiplication and survival. As reported, levels of protease inhibitors are found to be in very low concentration in these sites. Overall, a high degree of variation is seen in these compartments in terms of drug concentration. ${ }^{6}$

\section{Macrophages}

Macrophages isolated from the intestine have shown to be one of the potent sanctuary sites for HIV. Zalar et al reported a detectable level of virus from the duodenum despite the fact that plasma showed the virus as undetectable. These macrophages have a very high propensity towards spread to the central nervous system. ${ }^{24}$ Also, the fact that macrophages expressed efflux transporters like P-gp and MRP did never allow the concentration of anti-retrovirals to build inside these macrophages to reach levels sufficient enough to kill the virus. This could be one of the reasons as to why macrophages serve as excellent sanctuary sites. ${ }^{2}$

\section{Lymph node}

Horiike et al have reported the mesenteric lymph nodes as a possible sanctuary site for human immune-deficiency virus based on their study in anti-retroviral drugs treated macaques. In fact detectable levels of virus were reported from the inguinal, iliac and cervical lymph nodes too, even in the presence of long term anti-retroviral treatment. ${ }^{2,25}$

\section{Possible sanctuary sites for metastatic cancer cells}

One of the most important sanctuary sites as far as cancer cells are concerned is the CNS. It is even more important because of the fact that once metastasis has reached the brain or CNS the prognosis becomes very poor. Most common cancer leading to metastasis to brain are lung and breast cancer. It is widely known that most of the chemotherapeutic agents cannot get past the blood brain barrier and this is one of the major reasons for metastatic cells thriving inside the CNS. It is for this reason only that metastasis to CNS is famous for producing relapses, because the malignant cells get unopposed chance to proliferate at their own pace. Also factors determining angiogenesis plays a very important role in case of metastasis and with brain being a highly vascular organ this becomes even more facilitated. ${ }^{26}$

Another important and possible site which acts as a sanctuary compartment for cancers like merkel cell carcinoma is testis. Though it is very rare the instances of testicular metastasis have been reported and merkel cell carcinoma being a very aggressive form of cancer cannot be ignored. Possible reason for the testis to act as a sanctuary site could be first and foremost because of the presence of the blood-testis barrier, and the other being the presence of efflux pumps like P-gp present in the capillary endothelium and MRP-1 on sertoli cells. ${ }^{27}$

Cases of relapse of acute lymphoblastic leukaemia (ALL) too have been reported in the epididymis. This underlines the importance of testis as a potential sanctuary site because it is protected from the systemic circulation to a great extent by virtue of the blood-testis barrier. ${ }^{28}$ 
Another location which could act as sanctuary site leading to relapse of cancer is breast. As per reports the graft versus leukaemia action of the cells acting on the donor cells in case of haematopoietic stem cell transplants can lead to relapse of ALL in the breast tissue. ${ }^{29}$

\section{WHY SHOULD WE BE WARY ABOUT SANCTUARY COMPARTMENTS?}

There is ample evidence available at hand regarding the fact that the sites which act as reservoirs for drugs in the body do keep releasing it over a prolonged interval of time. This leads to constant exposure to the drug which over an extended period of time can be damaging. For instance, Adipose tissues sequestering the organic pollutants like DDT may protect the rest of the body from being exposed to it but the accumulation will increase the burden on the body and finally leads to weight loss, metabolic effects and induction of pro-inflammatory states in the body. ${ }^{11}$

Similarly, a drug like digoxin which deposits in the muscle tissues can be displaced from the site in presence or coadministration of other drugs like Amiodarone or Flecainide which could lead to digoxin toxicity. Thus, a careful monitoring of the patient and watchfulness for possible signs of digoxin overload have to be watched out for. ${ }^{8}$

When it comes to sanctuary sites for HIV and the plight of anti-retroviral drugs, the most important and probably the most dreadful of all the factors is the development of resistance amongst the virus towards the existing antiretrovirals. ${ }^{6}$ The reason for this is unopposed shelter and proliferation of the virus in the sanctuary compartments like genital tracts, where the anti-retrovirals do not reach optimal concentration. These sub-therapeutic levels could not check virus proliferation and it has also been observed that this has given the virus an ability to acquire favourable mutations which has led to development of resistance and rebound of the disease state at times. It has been reported that about one-third of the patients receiving ART have shown failure to respond adequately or have shown a rebound within a year of starting the ART. ${ }^{30}$

It is clearly evident that existence of an anatomical compartment like female or male genital tract where the HIV resides in the cervico-vaginal secretions or seminal fluids is proving to be the roadblock in eradicating the human immunodeficiency virus from the body. ${ }^{6}$

Compartmentalisation of the CNS as a sanctuary site poses another serious hurdle in countering the HIV progress. HIV once inside the CNS can initiate HIV associated neurocognitive dysfunction and this may happen quite early during the infection. As the HIV can undergo neuroadaptation, the anti-retrovirals need to be quite effective in checking the resistance profile of these virus but owing to their poor permeability the concentration of majority of the anti-retrovirals in the CSF does not reach therapeutic levels. While certain anti-retrovirals like Zidovudine, Abacavir, Nevirapine, Darunavir and Raltegravir showed optimum levels in the CSF thus indicating efficient penetration in the CNS, satisfactory enough to check the multiplication of the virus there are a significant number of anti-retrovirals too, which fail to do so. For example- Tenofovir, Efavirenz, Protease Inhibitors like Saquinavir, Atazanavir and Enfuvirtide have been disappointing in this regard as they have failed to reach levels in the CSF which could help in checking the viral multiplication. ${ }^{31}$

Acquired resistance to the anti-cancer drugs happens to be an important challenge for clinicians today. Spatial heterogeneity of the anti-cancer drugs in reaching the desired site especially sanctuary sites like CNS where metastatic cells take refuge has contributed to the development of resistance and failure of therapy. This heterogeneity is one of the major contributors to the development of resistance and presence of sanctuary sites having poor reach of drugs have contributed to this by speeding up the process of acquired resistance to cancer chemotherapy. Another dreadful fact being the resistance which starts in the sanctuary sites can easily progress to populate other locations in the body too. ${ }^{32}$

\section{WAYS TO CONQUER THE SANCTUARY SITES}

\section{Deriving specific therapy targeted towards the particular compartment}

Target specific approach in terms of compartment targeting can help eliminating HIV from the body by acting within these sanctuaries. ${ }^{2}$ Administration of the antivirals locally at the desired sanctuary sites could provide benefit as suggested by studies where local administration of Tenofovir was done intra-vaginally and intra-rectally in primates and it showed detectable levels of the anti-retroviral drugs even after 24 hours of administering the drug. ${ }^{33}$

Another study applying 1\% Tenofovir gel in the monkey vagina showed supra-optimum levels of lymphocytes in the vagina after 24 hours. This was a very encouraging finding as far as attaining desired levels of lymphocytes in the genital tract was concerned. ${ }^{34}$

\section{Blocking of the transporters and the metabolism of the drugs}

Various means to increase the concentration of drug in these sanctuary sites have been tried.

Ritonavir and Cobicistat have shown to inhibit CYP3A enzyme. Cell lines with human colorectal adenocarcinoma cells have demonstrated improved transport of antiretroviral drugs across the cells inside. This is done by inhibiting some efflux transporters too. Recently, a prodrug of Abacavir has shown inhibition of P-gp on the 
basis of in-vitro assay. This could even be tried for other anti-retroviral drugs. ${ }^{35,36}$

\section{Modifying the existing drugs and developing newer ones}

Better anti-retrovirals in terms of effective reach into the sanctuary sites need to be developed. Tenofovir Alafenamide Fumarate, a drug with better penetration into the lymphoid tissues is undergoing testing at present. With a higher dose this drug has shown greater absorption in comparison to lower dose. (The drug has reported to exhibit variable absorption) This ability of the drug could be attributed to saturation of the P-gp transporters in the intestine. Tenofovir Alafenamide Fumarate has shown up to 15 times higher concentration in the lymph nodes in comparison to the presently used molecule of Tenofovir. Similarly, it has also shown up to 150 times higher concentration in peripheral blood mononuclear cells in comparison to the plasma. ${ }^{2,37}$

Another noteworthy development is seen with Zidovudine. It was observed that a conjugate of Zidovudine and Ursodeoxycholic acid forms a complex which can easily cross the blood brain barrier. Thus, the conjugate can lead to a higher concentration of the drug Zidovudine inside the CNS. $^{2}$

\section{Use of nanotechnology}

The concept of nano anti-retroviral therapy has been emerging off late. Anti-retrovirals are prepared with size $<100 \mathrm{~nm}$, thus intending to increase the reach of the drugs within the sanctuary sites. ${ }^{2}$

Macrophages coming in contact with nano anti-retroviral drugs show rapid uptake of the anti-retroviral drugs and release it slowly. Thus in addition to the abovementioned advantage these nano anti-retrovirals can also provide with the option of less frequent dosing. Even tissues like liver, spleen, and kidneys have shown significant concentration of nano anti-retrovirals several days after administration. ${ }^{38}$

The lipid-Indinavir nanoparticle complex was tested on macaques and they showed about 6 times increased concentration in the lymph nodes. Thus, denoting the fact that this complex can get sequestrated in the lymph nodes and counter their potential as a sanctuary site. Similarly, peptide coated nanoparticle and Indinavir have also showed higher antiviral activity and a higher sequestration in the cells. ${ }^{2}$

The overcome the problems posed by the cancer cells metastasising to the sanctuary sites like CNS, very little is available on offer

Treating brain metastasis is one of the crushing challenges faced by the modern day clinicians. Significant improvements can only be seen if drugs are able to penetrate the blood-brain barrier and blood-tumor barrier efficiently. Though modalities like use of radio surgery and whole brain radiotherapy (WBRT) have become popular especially in case of metastasis caused by small cell lung cancers and WBRT has also helped in the sense that it has shown to increase the blood-brain permeability thus enabling concomitant chemotherapy to reach the CNS. But, the most efficient way of countering the phenomena of metastasis to sanctuary sites as far as cancer cells are concerned is to have a better and efficient understanding of brain metastasis through better preclinical models. ${ }^{39}$

Brain metastasis is the seeding of the cells in the vasculature of the CNS. It is difficult to develop the exact human replica of migration and invasion because of many other factors like immune system and hemodynamics come into the picture in addition to the most important obstacle, the blood-brain barrier. ${ }^{39}$

\section{CONCLUSION}

It is obvious that pharmacologic sanctuaries are a major obstacle in getting the desired treatment response with HIV positive individuals. As long as these sanctuaries remain unconquered anti-retroviral levels will always be in a suboptimal range. Amongst the options available to circumvent the sanctuary compartments, presently nanotechnology seems to hold much promise. Yet, continuous research in this direction is required and should be pursued if a reasonable answer and a substantial step in this direction needs to be arrived at.

Cancer pathogenesis and CNS metastasis follow a complex mechanism. It is very important and vital to understand what all goes into CNS metastasis through better metastatic animal models, as this only can help in coming up with best possible modalities to manage the condition. Apart from this other significant step in the right direction would be inclusion of the patients with CNS metastasis in the clinical trials. This would help in getting the real situation to work around and though it may seem unethical to some, it seems to be the most effective means of improvement presently.

\section{Funding: No funding sources \\ Conflict of interest: None declared \\ Ethical approval: Not required}

\section{REFERENCES}

1. Clavel C, Peytavin G, Tubiana R, Soulié C, Courbon $\mathrm{E}$, Crenn-Hebert C, et al. Etravirine concentrations in the cervicovaginal compartment in HIV-1-infected women receiving etravirine-containing antiretroviral therapy: DIVA 02 study. Antimicrob Agents Chemother. 2012;56(7):4018-20.

2. Cory TJ, Schacker TW, Stevenson M, Fletcher CV. Overcoming pharmacologic sanctuaries. Curr Opin HIV AIDS. 2013;8(3):190-5.

3. Buxton ILO. Pharmacokinetics: The Dynamics of Drug Absorption, Distribution, Metabolism, and 
Elimination. In: Brunton LL, Hilal-Dandan R, Knollmann BC (eds) Goodman and Gillman's the pharmacological basis of therapeutics, $13^{\text {th }} \mathrm{Edn}$. Mc Graw-Hill, New York; 2018:18.

4. Buxton ILO. Pharmacokinetics: The Dynamics of Drug Absorption, Distribution, Metabolism, and Elimination. In: Brunton LL, Hilal-Dandan R, Knollmann BC (eds) Goodman and Gillman's the pharmacological basis of therapeutics, $13^{\text {th }} \mathrm{Edn}$. Mc Graw-Hill, New York; 2018:19.

5. Crabb S, McKendrick JJ, Mead GM. Brain as sanctuary site of relapse in germ cell cancer patients previously treated with chemotherapy. Clin Oncol. 2002;14(4):287-93.

6. Else LJ, Taylor S, Back DJ, Khoo SH. Pharmacokinetics of antiretroviral drugs in anatomical sanctuary sites: the male and female genital tract. Antivir Ther. 2011;16(8):1149-67.

7. Else LJ, Taylor S, Back DJ, Khoo SH. Pharmacokinetics of antiretroviral drugs in anatomical sanctuary sites: the fetal compartment (placenta and amniotic fluid). Antivir Ther. 2011;16(8):1139-47.

8. Hartshorn EA, Hartshorn JC. Factors affecting digoxin action and kinetics. J Cardiovasc Nurs. 1988;2(4):129.

9. Thaxton CS, Rink JS, Naha PC, Cormode DP. Lipoproteins and lipoprotein mimetics for imaging and drug delivery. Adv Drug Deliv Rev. 2016;106(Pt A):116-31.

10. Colombo MI, Bertini F. Properties of binding sites for chloroquine in liver lysosomal membranes. J Cell Physiol. 1988;137(3):598-602.

11. La Merrill M, Emond C, Kim MJ, Antignac JP, Le Bizec B, Clément K, et al. Toxicological function of adipose tissue: focus on persistent organic pollutants. Environ Health Perspect. 2013;121(2):162-9.

12. Mühlebach S, Wyss PA, Bickel MH. Comparative adipose tissue kinetics of thiopental, DDE and $2,4,5,2^{\prime}, 4^{\prime}, 5^{\prime}$-hexachlorobiphenyl in the rat. Xenobiotica. 1985;15(6):485-91.

13. Cagini C, Piccinelli F, Lupidi M, Messina M, Cerquaglia A, Manes S, et al. Ocular penetration of topical antibiotics: study on the penetration of chloramphenicol, tobramycin and netilmicin into the anterior chamber after topical administration. Clin Exp Ophthalmol. 2013;41(7):644-7.

14. Mindel JS, Smith H, Jacobs M, Kharlamb AB, Friedman AH. Drug reservoirs in topical therapy. Invest Ophthalmol Vis Sci. 1984;25(3):346-50.

15. Suhara T, Sudo Y, Yoshida K, Okubo Y, Fukuda H, Obata T, et al. Lung as reservoir for antidepressants in pharmacokinetic drug interactions. Lancet. 1998;351(9099):332-5.

16. Stepensky D, Kleinberg L, Hoffman A. Bone as an effect compartment: models for uptake and release of drugs. Clin Pharmacokinet. 2003;42(10):863-81.

17. Elewski BE. Onychomycosis: pathogenesis, diagnosis, and management. Clin Microbiol Rev. 1998;11(3):415-29.
18. Seif S, Hansen S. Measuring the stratum corneum reservoir: desorption kinetics from keratin. J Pharm Sci. 2012;101(10):3718-28.

19. Pomerantz RJ. Reservoirs, sanctuaries, and residual disease: the hiding spots of HIV-1. HIV Clin Trials. 2003;4(2):137-43.

20. Palmieri D, Chambers AF, Felding-Habermann B, Huang S, Steeg PS. The biology of metastasis to a sanctuary site. Clin Cancer Res. 2007;13(6):1656-62.

21. Chun TW, Nickle DC, Justement JS, Meyers JH, Roby G, Hallahan CW, et al. Persistence of HIV in gutassociated lymphoid tissue despite long-term antiretroviral therapy. J Infect Dis. 2008;197(5):71420.

22. Englund G, Rorsman F, Rönnblom A, Karlbom U, Lazorova L, Gråsjö J, et al. Regional levels of drug transporters along the human intestinal tract: coexpression of $\mathrm{ABC}$ and SLC transporters and comparison with Caco-2 cells. Eur J Pharm Sci. 2006;29(3-4):269-77.

23. Nicol MR, Kashuba AD. Pharmacologic opportunities for HIV prevention. Clin Pharmacol Ther. 2010;88(5):598-609.

24. Zalar A, Figueroa MI, Ruibal-Ares B, Baré P, Cahn P, de Bracco MM, et al. Macrophage HIV-1 infection in duodenal tissue of patients on long term HAART. Antiviral Res. 2010;87(2):269-71.

25. Horiike M, Iwami S, Kodama M, Sato A, Watanabe Y, Yasui M, et al. Lymph nodes harbor viral reservoirs that cause rebound of plasma viremia in SIV-infected macaques upon cessation of combined antiretroviral therapy. Virology. 2012;423(2):107-18.

26. Palmieri D, Chambers AF, Felding-Habermann B, Huang S, Steeg PS. The biology of metastasis to a sanctuary site. Clin Cancer Res. 2007;13(6):1656-62.

27. Tummala MK, Hausner PF, McGuire WP, Gipson T, Berkman A. CASE 1. Testis: a sanctuary site in Merkel cell carcinoma. J Clin Oncol. 2006;24(6):1008-9.

28. Bourne AE, Wayment RO, Tarter TH, Hemmer P. Isolated relapse of acute lymphoblastic leukemia in the epididymis: a rare sanctuary site. J Clin Oncol. 2010;28(20):e327-8.

29. Thanka J, Krishnarathinam K, Rajendiran S. Extramedullary relapse of acute lymphoblastic leukemia in breast: a rare presentation. Indian J Pathol Microbiol. 2010;53(1):155-6.

30. Benzie AA, Bansi LK, Sabin CA, Portsmouth S, Hill $\mathrm{T}$, Johnson $\mathrm{M}$, et al. Increased duration of viral suppression is associated with lower viral rebound rates in patients with previous treatment failures. AIDS. 2007;21(11):1423-30.

31. Ene L, Duiculescu D, Ruta SM. How much do antiretroviral drugs penetrate into the central nervous system? J Med Life. 2011;4(4):432-9.

32. Fu F, Nowak MA, Bonhoeffer S. Spatial heterogeneity in drug concentrations can facilitate the emergence of resistance to cancer therapy. PLoS Comput Biol. 2015;11(3):e1004142. 
33. Nuttall J, Kashuba A, Wang R, White N, Allen P, Roberts J, et al. Pharmacokinetics of tenofovir following intravaginal and intrarectal administration of tenofovir gel to rhesus macaques. Antimicrob Agents Chemother. 2012;56(1):103-9.

34. Dobard C, Sharma S, Martin A, Pau CP, Holder A, Kuklenyik Z, et al. Durable protection from vaginal simian-human immunodeficiency virus infection in macaques by tenofovir gel and its relationship to drug levels in tissue. J Virol. 2012;86(2):718-25.

35. Xu L, Liu H, Murray BP, Callebaut C, Lee MS, Hong A, et al. Cobicistat (GS-9350): a potent and selective inhibitor of human CYP3A as a novel pharmacoenhancer. ACS Medicinal Chem Lett. 2010;1(5):209-13.

36. Namanja HA, Emmert D, Davis DA, Campos C, Miller DS, Hrycyna CA, et al. Toward eradicating HIV reservoirs in the brain: inhibiting P-glycoprotein at the blood-brain barrier with prodrug abacavir dimers. J Am Chem Soc. 2012;134(6):2976-80.

37. Lee WA, He GX, Eisenberg E, Cihlar T, Swaminathan $\mathrm{S}$, Mulato A, et al. Selective intracellular activation of a novel prodrug of the human immunodeficiency virus reverse transcriptase inhibitor tenofovir leads to preferential distribution and accumulation in lymphatic tissue. Antimicrob Agents Chemother. 2005;49(5):1898-906.

38. Nowacek AS, McMillan JE, Miller R, Anderson A, Rabinow B, Gendelman HE. Nanoformulated antiretroviral drug combinations extend drug release and antiretroviral responses in HIV-1-infected macrophages: implications for neuro AIDS therapeutics. J Neuroimmune Pharmacol. 2010;5(4):592-601.

39. Puhalla S, Elmquist W, Freyer D, Kleinberg L, Adkins $\mathrm{C}$, Lockman $\mathrm{P}$, et al. Unsanctifying the sanctuary. Challenges and opportunities with brain metastases. Neuro Oncol. 2015;17(5):639-51.

Cite this article as: Amar A. Sanctuary sites and compartments: deciphering the enigma. Int J Basic Clin Pharmacol 2018;7:1208-14. 